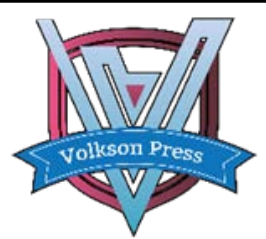

Contents List available at Volkson Press

Economics, Business and Management (EBMan)

DOI : http://doi.org/10.26480/wsebm.01.2017.04.05

\title{
ANALYSIS ON ADVANTAGES AND DISADVANTAGES OF POSTPONING THE RETIREMENT AGE IN CHINA
}

\author{
Feng Naiwen \\ North China Electric Power University, Beinong Street, Beijing, China \\ *Corresponding Author Email: 18601193159@163.com
}

This is an open access article distributed under the Creative Commons Attribution License, which permits unrestricted use, distribution, and reproduction in any medium, provided the original work is properly cited.

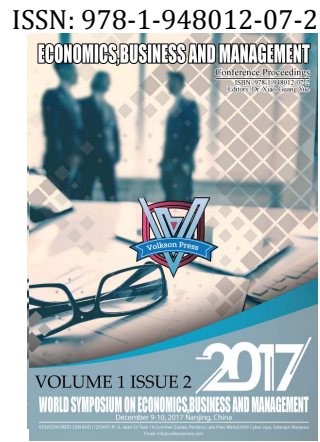

\section{ARTICLE DETAILS}

\section{ARTICLE HISTORY:}

Received 27th December 2017

Accepted 29th December 2017

Available online 29th December 2017

\section{KEYWORDS:}

Retirement Age, Population Aging, Postponing, Analysis of Advantages and Disadvantages

\section{ABSTRACT}

With the growth in living standard, the obvious enhancement in population quality and the great improvement in medical and sanitation facilities, the life expectancy has risen increasingly in China and the problem of population aging has become more and more prominent. The current retirement system of China is one carried out in the 1950s, so the formulation and implementation of the policy about postponing the retirement age has become one of the hot spots of society. This paper, taking the subject of postponing the retirement age as the background, mainly analyzes the advantages and disadvantages of postponing the retirement age and proposes a comprehensive analysis both on the implementation of the policy and on the opinions from all walks of life.

\section{INTRODUCTION}

The current retirement system is one carried out in the 1950s, which refers to that the retirement age is 60 for males and 55 for females. However, the life expectancy of Chinese people was about 50 when this policy was formulated. Now, half a century later, we have witnessed a great growth in living standard and an obvious enhancement in population quality with the rapid development of China's economy, so the relevant problems, such as the reasonability of the previous retirement system and the advantages and disadvantages of postponing the retirement age, etc., have become the hot spots of society [1]. As He Ping, the director of Social Security Institute, Ministry of Human Resources and Social Security of the People's Republic of China, said on July 1st, 2015, China shall postpone the retirement age gradually. He suggests that the policy of postponing the retirement age shall be carried out in 2016 and the retirement age shall be raised 1 year old for every two years till the retirement age both of males and females reaches 65 in 2045. However, before the discussion about this subject, I think it's necessary for us to understand that the legal retirement age, as we like to say, refers to the retirement age that was approved in the second Standing Committee of the fifth National People's Congress on May 24th, 1978 and that is still valid according to the State Council's Interim Procedures Concerning the Resettlement of the Cadres Who are Old, Weak, Sick and Disabled and the State Council's Interim Procedures Concerning the Retirement and Resignation of Workers (GF 【1978】 No.104). At present, the legal retirement age is 60 for males, 55 for female cadres and 50 for female workers [2].

\section{2.}

ADVANTAGES OF POSTPONING THE RETIREMENT AGE

The postponement of the retirement age can relieve the pressure of the old-age pension, narrow the gap of the old-age pension, and further relieve the financial pressure of the government. These effects are conspicuous. As we know, at some point, the total amount of the old-age pension that shall be paid is positively associated with the number of people who have the right to draw the old-age pension. In other words, the total amount of the old-age pension that shall be paid will grow increasingly with the increase of the retired population in a certain period, and with the deepening of aging, there are more and more retired people whose old-age pension shall be supported by the young people who need to work. Recently, the American "Bloomberg Sunset Index" shows that China ranks fifth among the countries with the greatest risk of population aging in the world. The global aging is not a new topic. Especially, facing the great change of family structure, the problem of aging before getting rich has become a social concern in China. With the increase of the aged population, the retirement pressure of the old themselves and the supporting pressure of the young get increasingly serious.

As reports show, the shrinkage rate of the proportion of laboring population is faster than expected in the world, and fewer and fewer middle-young people have to take care of more and more old people. France and Singapore rank first and second among the countries with the greatest risk of population aging in the world respectively, with every 2.2 in-service staff supporting 1 retiree averagely. And Russia (2.4:1) and Thailand (2.6:1) are close behind. In China, every 3.5 labor force shall support the old-age pension of 1 retiree averagely, but the reasonable situation shall be that every 7.3 people support the expenditure of 1 old person. Therefore, in the present situation with an irreversible trend of population aging, it's relatively feasible to relieve the increasingly great pressure of the old-age pension, make up for the gap of the old-age pension and relieve the financial pressure of the local government by postponing the retirement age in the short term.

The postponement of the retirement age can increase the use ratio of human capital and further optimize the labor force and deal with the disappearance of "Demographic Dividend", especially in the resource allocation of high-quality talents. With the gradual improvement in medical and sanitation facilities, the life expectancy of Chinese people increases constantly (with the detailed situation as shown in the following chart). And most people in their 50s and 60s still have the good physical state and mental outlook, so they are able to stick at their jobs absolutely. As for the industries that need highly-competent 
people, such as aeronautics and astronautics and medicine, etc., the staff with richer experience will play an important role in promoting the industrial development. In other words, retiring early from work will not only lead to the brain drain to a certain extent, but also reduce the use ratio of human capital. What's more, some old retirees who still have the labor capacity will have a strong sense of loss if they sit around after retirement, which has an adverse influence on their physical and psychological health.

The postponement of the retirement age is also a reflection both in the improvement of national quality and in the enhancement of comprehensive national power. According to the existing data, we have found that the average retirement age in most developed countries is higher than that in the developing countries. For example, the legal retirement age in UK is 65; and the retirement age is 65 for male Italians and 60 for female Italians. So the postponement of the retirement age can reflect the comprehensive improvement of the population quality in a certain aspect. Besides, the retirement system is sounder in developed countries that carry out the reform based on the idea of postponing the retirement age, so it's one of the inexorable trends for the world to postpone the retirement age during the reform of retirement system.

Table 1: 2010-2015 The Change of Average Future Life

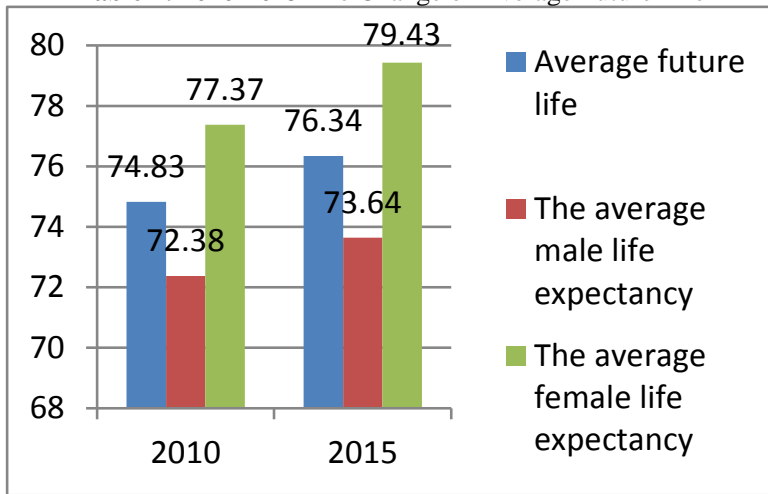

(All the data above are from the National Bureau of Statistics of the People's Republic of China)

\section{DISADVANTAGES OF POSTPONING THE}

\section{RETIREMENT AGE}

The postponement of the retirement age will increase the employment pressure of young people. One of the grave consequences is that the postponement of the retirement age will increase the employment pressure. According to the data from the National Bureau of Statistics of the People's Republic of China, in 2015, the urban employed people are 404,100,000 and the retired people are 75,312,000, accounting for a great proportion of $18 \%$ in the number of urban employed people. Just think, a large proportion of posts will be cut down if the retirement age is raised, which may lead to the unemployment of a part of people accordingly and increase the unemployment rate euphemistically. From the perspective of enterprises, the postponement of the retirement age will limit the room for young people's innovation and improvement to a certain extent, which goes against the long-term development of enterprises.

Table 2: Changes of the Economically Active Population in Recent Five Years

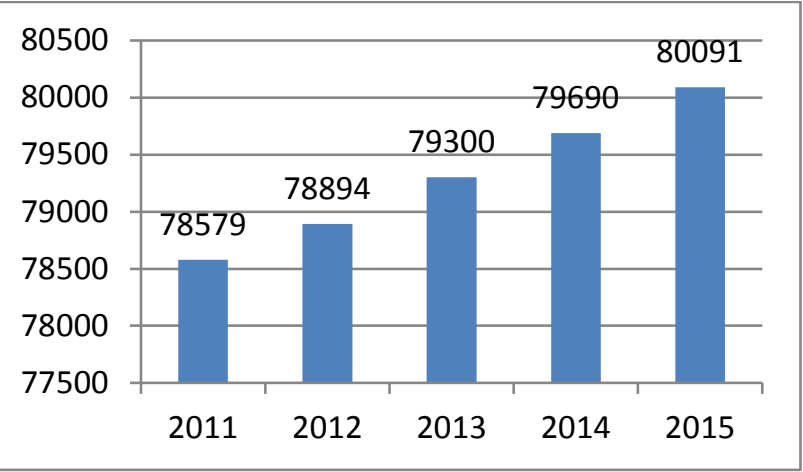

(All the data above are from the National Bureau of Statistics of the
People's Republic of China)

The postponement of the retirement age will aggravate the life pressure of the social vulnerable group. Those, doing gravy jobs but with high income, don't want to postpone the retirement age, because they, with high income and good welfare, will not care about the premium that they have to pay every month. But as for the vulnerable group with poor working environment, heavy working intensity and low income, there's not much money left after paying a series of premiums, so of course, they want to retire early to relieve the pressure of paying high premium for each month in front of the soaring prices and huge household expenditure. In today's society of China, a large number of laid-off workers face the difficult to get reemployed for various reasons. These people, who, mostly in 40s and 50s, have the duty to support their parents and kids at the same time, expect to take the old-age pension early to relieve their life pressure.

The postponement of the retirement age will bring more benefits to a part of interest groups. These interest groups, mainly referring to the government officials with the real power, certainly want to postpone the retirement age so as to seek more gains by taking advantage of their power. This situation will further widen the gap between the rich and the poor, which is more adverse to the social equity.

\section{COMPREHENSIVE ANALYSIS}

With the rapid development of the society, economy and culture and the great improvement of the medical level in China, the life expectancy has extended to a large extent. The population of the middle aged and elderly people accounts for a large proportion of China's age structure and the trend of population aging is irreversible. It will be unreasonable to stick to the retirement age specified previously, so the proposal to postpone the retirement age is inevitable and reasonable to a certain extent. Besides, the serious problem of employment difficulty in China is actually the structural contradiction between the labor supply and the labor demand, rather than the problem that the postponement of the retirement age will squeeze the labor supply and demand as most people think seemingly. According to the statistics, the number of job vacancy is greater than that of job seekers in 2015 (as shown in the following chart), which reflects the above-mentioned problem in a certain aspect. However, the proposal and implementation of any policy is a double-edged sword. The dissenting opinion about the postponement of the retirement age is not only caused by the policy itself, but also is related to China's pension system, education system and talent cultivation, etc. Therefore, it's indispensable to weight the advantages and disadvantages, guarantee the benefit of the mass and ensure the social equity to the utmost extent when the policy is implemented in China.

Table 3: Supply and Demand of the Labor Market in 2015

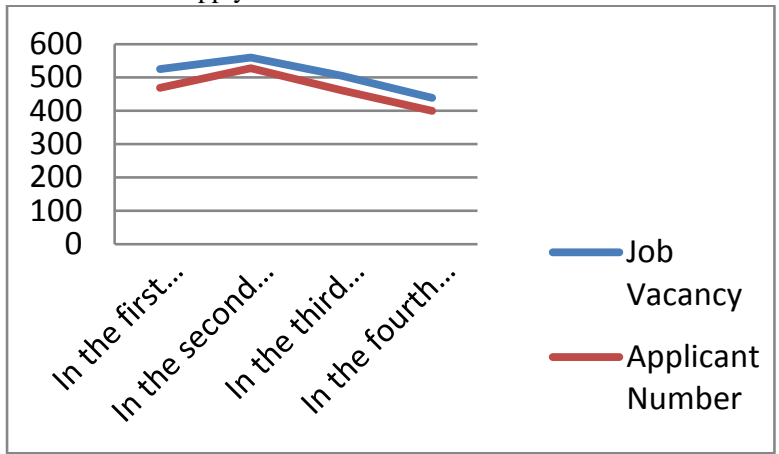

(All the data above are from the National Bureau of Statistics of the People's Republic of China)

\section{References:}

[1] Bao, L. 2014. Population Ageing and the Sustainability of Urban Basic Old-age Insurance[M]. China Social Science Press.

[2] Yi, L. 2015. Management of Social Insurance Fund [M]. China Labor Social Security press. 